\title{
Centros de Serviços Compartilhados: da experiência britânica às perspectivas de inovação na Gestão Pública Brasileira
}

Cicero Ferreira, Luiz Paulo Bresciani e Leonel Mazzali

\section{Introdução}

Os centros de serviços compartilhados são cada vez mais utilizados na gestão pública. Órgãos e departamentos públicos em países como Canadá, Estados Unidos, Austrália, Irlanda, Escócia, Inglaterra, Holanda, Alemanha, França, Itália, Espanha, África do Sul e Singapura alcançaram a melhoria dos serviços públicos e a redução dos custos associados, utilizando centros de serviços compartilhados. Nessa forma de organização, os serviços, como suprimentos, finanças e recursos humanos, são retirados de suas áreas originais e concentrados em um centro de serviços compartilhado, aqui tratado pela sigla CSC.

Dado o seu caráter inovador na administração pública e o fato das iniciativas no Brasil ainda se encontrarem em fase embrionária, pretende-se apresentar e discutir a teoria e a prática de centros de serviços compartilhados, tendo como foco três questões centrais: 
1) quais os fatores determinantes de seu surgimento?

2) quais os principais problemas em sua implantação?

3) quais as tendências dos CSC na gestão pública?

Busca-se oferecer um conjunto de parâmetros para a discussão teórica e formulação de políticas voltadas à implementação de CSC no setor público, a partir de um estudo exploratório, o qual, segundo Selltiz et al. (1974), além de ter "como objetivo a formulação de um problema para investigação mais exata ou para a criação de hipóteses", pode ter:

outras funções: aumentar o conhecimento do pesquisador acerca do fenômeno...; o esclarecimento de conceitos; o estabelecimento de prioridades para futuras pesquisas; ... (SELLTIZ et al., 1974, p. 60).

A proposta do trabalho é reunir, a partir de pesquisa bibliográfica, um conjunto de elementos que permitam responder às três questões colocadas, conduzindo a reflexão sobre alguns dos possíveis espaços dos centros de serviços compartilhados na administração pública.

$\mathrm{O}$ esforço se voltou, em primeiro lugar, para o exame da literatura pertinente, recorrendo-se, principalmente, às seguintes bases de dados:

a) ProQuest, Web of Science, Scielo, Inderscience, ScienceDirect e Emerald;

b) Revista de Administração da USP, Revista de Administração Pública e Revista do Serviço Público;

c) publicações especializadas em seminários e congressos científicos, destacando-se o SemeAd, Seminários em Administração e o EnAnpad, Encontro da Anpad; d) World Bank e Fundação para o Desenvolvimento Administrativo do Governo do Estado de São Paulo (Fundap); e

e) Site específico dos CSC do governo inglês.

Dentre a produção científica analisada, destacam-se os artigos de Janssen e Joha (2006, 2007 e 2008), que desenvolvem uma linha de pesquisa específica sobre os CSC na gestão pública, na Delft University of Technology, Holanda.

Em segundo lugar, os pontos destacados a partir da revisão bibliográfica, procedimento metodológico básico, dada a natureza deste trabalho, foram reforçados levando-se em conta a análise da experiência britânica. Vale destacar que, na GrãBretanha, o compartilhamento de serviços avançou de forma considerável, resultando na criação de políticas públicas específicas e infraestruturas nacionais. (TOMKINSON, 2007).

O trabalho está estruturado em seis seções. A primeira é introdutória. A segunda discute o conceito de centros de serviços compartilhados. A terceira apresenta a origem e a evolução do centro de serviços compartilhado no setor privado. A quarta analisa a utilização dos centros de serviços compartilhados pelo setor público. A quinta avalia a experiência britânica com centros de serviços compartilhados no serviço público. Finalmente, as considerações finais apresentam, além das conclusões da pesquisa, as tendências dos centros de serviços compartilhados na gestão pública.

\section{Centros de serviços comparti- lhados: conceituação}

O conceito de centros de serviços compartilhados varia tanto em abrangência como em foco, sendo identificadas, na literatura, três acepções. 
$\mathrm{Na}$ primeira acepção, o CSC envolve a concentração dos recursos voltados ao processamento de atividades comuns e repetitivas, as quais se encontram espalhadas pela organização. O objetivo é a redução de custo e o aprimoramento do nível dos serviços oferecidos aos denominados clientes internos. (Schulman et al, 1999).

$\mathrm{Na}$ segunda interpretação, unidades de negócios decidem compartilhar um conjunto de serviços, ao invés de tê-lo como uma série de funções de apoio duplicadas dentro da organização (QuinN; COOKE; Kris, 2000).

$\mathrm{Na}$ terceira, o CSC constitui-se em uma estratégia de colaboração, na qual um subconjunto de funções de negócio é concentrado em uma nova unidade semiautônoma. O CSC possui estrutura de gestão voltada ao aumento da eficiência, à geração de valor, à redução de custos e à melhoria dos serviços para os clientes internos da corporação. (BERGERON, 2003).

Para que o CSC funcione adequadamente alguns requisitos são essenciais. Em primeiro lugar, a unidade de serviços CSC precisa ser semiautônoma, não respondendo hierarquicamente a nenhum de seus clientes, embora esses devam participar de sua governança, tendo em vista o direcionamento e a avaliação de resultados. Em segundo lugar, o CSC deve buscar a melhoria contínua e atuar em conformidade com as melhores práticas de mercado, constituindo-se em um centro de excelência para os serviços constantes em seu portfólio. Em terceiro lugar, o CSC deve cobrar pelos serviços prestados, pois deve ser conduzido como uma unidade de negócios. Em quarto lugar, deve haver alto grau de automação, para que os benefícios de redução de custos e elevação da qualidade dos serviços possam ser atingidos (Schulman et al, 1999).
Janssen e Joha (2007) utilizam arcabouço conceitual centrado nas relações cliente-fornecedor para analisar as relações entre as unidades de negócio (clientes) e o centro de serviços compartilhado (fornecedor). Nessa abordagem, o centro de serviços compartilhado é considerado como um "arranjo cooperativo de serviços", possibilitando entender como o comportamento de cada ator contribui para a troca e como o compartilhamento dos

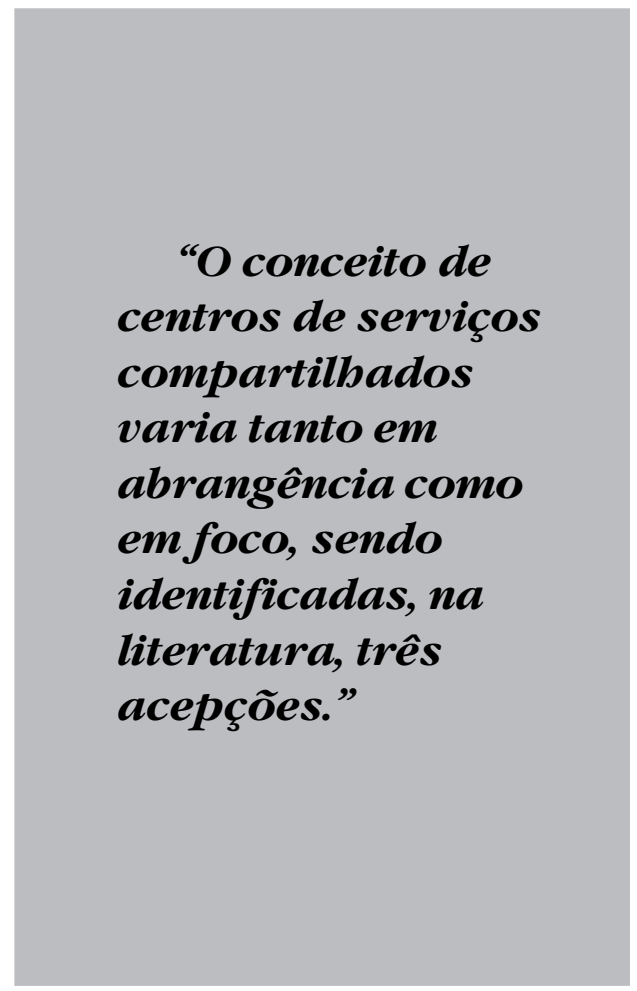

serviços depende da cooperação de todos os agentes envolvidos. Os contratos regem a especificação das trocas a serem efetivadas por meio de um arranjo de serviços compartilhados.

$\mathrm{O}$ arcabouço oferecido pelos referidos autores abrange as principais interações entre os clientes internos e o fornecedor (centro de serviço compartilhado), conforme 
representado na Figura 1, contempladas em três dimensões: do contexto, das interações e comportamental. comportamentais, como comprometimento, confiança, satisfação e expectativas dos agentes. O comprometimento e a confiança

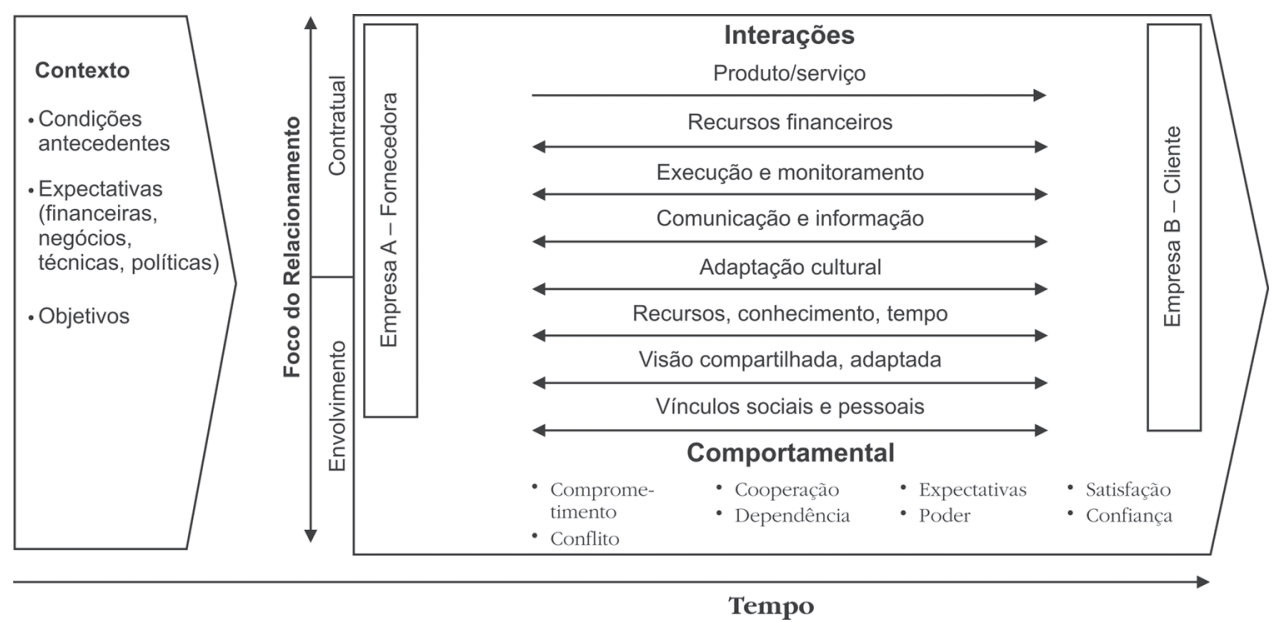

Figura 1: Modelo conceitual do relacionamento cliente-fornecedor nos CSC (JaNSSEN; JoHA, 2007)

A relação entre o CSC e os seus clientes depende da dimensão contextual, que inclui os objetivos específicos e as expectativas (financeiras, comerciais, técnicas e políticas). O contexto reflete as condições antecedentes, as quais são filtradas no contrato, que estabelece não só as dimensões de sucesso para o cliente, mas também as bases da relação.

As interações necessárias para a realização dos serviços entre o CSC e os clientes formam a segunda dimensão. Envolvem não só trocas financeiras e de informações, mas vínculos sociais e culturais necessários para institucionalizar o relacionamento cliente-fornecedor. Os autores chamam a atenção para esses vínculos, frequentemente não explícitos, subjacentes a regras, normas, processos, procedimentos e visões.

A forma e a frequência das interações, por sua vez, dependem do "clima organizacional", caracterizado por fatores podem se manifestar na alocação de especialistas, ou na regularidade com que a equipe do serviço compartilhado interage com os clientes.

Com base no arcabouço proposto por Janssen e Joha (2007), fica evidente que a implantação dos CSC envolve riscos e problemas que devem ser gerenciados adequadamente durante todo o ciclo de vida do projeto. Janssen e Joha (2008) dão ênfase aos seguintes problemas:

a) falta de participação e de motivação dos stakeholders (agentes interessados);

b) instabilidade e falta de especificação dos serviços;

c) ausência de interfaces com as unidades de negócio;

d) baixa qualidade, atrasos na entrega e aumento do custo dos serviços prestados pelo CSC; e

e) falta de mecanismos de governança.

Outros problemas também são referidos, como a perda de controle dos custos 
de implantação, despesas com infraestrutura, com realocação, contratação e treinamento de funcionários. Agrega-se ainda a necessidade de uniformizar sistemas de informação, administrar diferentes aspectos culturais e alinhar processos, demandando maior esforço do que o planejado inicialmente (Bain \& Company, 2004; DeloitTe, 2007). Bergeron (2003) ressalta a significativa mudança cultural requerida pelo CSC e seu custo inicial, que pode ser elevado.

A seguir resgata-se o surgimento dos centros de serviços compartilhados no contexto dos negócios privados.

\section{A origem e a evolução do centro de serviços compartilhado no setor privado}

Durante os anos 1970 as grandes corporações utilizavam o modelo centralizado de organização, principalmente para suas funções de suporte (como recursos humanos, finanças, tecnologia da informação e contabilidade). São apontados como pontos fortes do modelo centralizado: sistemas comuns, padrões e controles consistentes e economia de escala. Por seu turno, os pontos fracos seriam a passividade com relação às necessidades do negócio, os custos não controlados pelas áreas de negócio e sua inflexibilidade (Schulman et al, 1999).

$\mathrm{Na}$ década seguinte surgiram as unidades estratégicas de negócio (SBUs Strategic Business Units), ou simplesmente unidades de negócio, privilegiando o modelo descentralizado para as funções de suporte, em que cada unidade tinha liberdade de organizar-se como desejasse para atingir os objetivos. Em decorrência dessa descentralização passou a haver redundância de estruturas de suporte nas grandes corporações, o que elevou os custos operacionais. Os principais pontos fortes do modelo descentralizado são o controle da unidade de negócio sobre os serviços de suporte e a capacidade de reação às necessidades dos clientes. Como pontos fracos destacam-se a dificuldade de adoção de padrões na corporação, o surgimento de diversos tipos de controles, esforços de duplicação e altos custos.

É nesse contexto que a General Electric (GE) iniciou o desenvolvimento do modelo hoje conhecido como Centro de Serviços Compartilhado, tornando-se pioneira na sua utilização. Uma das principais características desse novo modelo organizacional é o fato de ser uma unidade semiautônoma de prestação de serviços (SCHUlman et al, 1999).

A partir da segunda metade dos anos 1990, o modelo CSC passou a ser aplicado como estratégia operacional, estando presente, na atualidade, na maioria das grandes corporações globais. Pesquisa realizada pela IBM Global Business Services (2008a), em cooperação com a Wharton School e o Economist Intelligence Unit, com mais de 1200 CFO e profissionais seniores de finanças em grandes empresas do mundo, revelou que mais de $50 \%$ dos respondentes adotam o CSC como prática efetiva em suas organizações. Outra pesquisa, realizada pela consultoria Bywater (2001), para o International Quality and Productivity Center, com 200 das 500 maiores empresas listadas pela revista Fortune, constatou que 97\% delas já utilizavam ou pretendiam utilizar os CSC.

Nascido nos Estados Unidos, o CSC teve pronta adesão em países europeus que rapidamente disseminaram o conceito entre suas empresas. No Brasil, nos últimos dez anos, houve expressivo aumento do número de organizações que passaram a adotar o CSC. Embora não existam números oficiais, observa-se, a cada evento ou congresso realizado sobre o tema, o 
aumento de empresas participantes, relatando suas experiências no uso dos CSC. No setor privado, no país, os centros de serviços compartilhados têm sido adotados por empresas como Grupo Algar, Panamericano, Petrobras, Grupo Pão de Açúcar, entre dezenas de outras, nacionais e multinacionais.

Pesquisa da consultoria Bain \& Company (2004), com 120 empresas que implantaram CSC nos últimos cinco anos, revelou quatro principais objetivos para sua adoção: redução de custos de overhead; melhoria da qualidade; precisão e cumprimento de prazos; padronização de processos; e otimização de capital de giro. Cabe ressaltar que, de modo geral, a literatura pesquisada enfatiza frequentemente dois aspectos, também mencionados nesta pesquisa, que são a melhoria na qualidade dos serviços e a redução de custos operacionais.

Com relação aos serviços prestados pelos CSC, no início se limitavam a atividades transacionais e repetitivas, normalmente associadas a funções financeiras e contábeis. Posteriormente, com o amadurecimento do modelo, outras atividades, como gestão de recursos humanos, tecnologia da informação, customer service, marketing e vendas, atividades administrativas, logística e suprimentos, foram incorporadas ao portifólio de serviços dos CSC (Schulman et al, 1999; Bergeron, 2003).

Depois da ampla utilização no setor privado, com a repercussão de casos de sucesso e o relato de reduções de custos, outras organizações, privadas e públicas, passaram a buscar a adoção desse modelo, como hospitais, Exército e Marinha norte americanos, a agência Nasa e governos em vários países europeus (Quinn; CoOKE; Kris, 2000; Bergeron, 2003). A seção seguinte aborda o interesse do setor público por essa inovação organizacional.

\section{Os centros de serviços compar- tilhados no serviço público}

Embora a literatura pesquisada não indique marco temporal no surgimento dos CSC na gestão pública, é possível fazer um paralelo entre o início da utilização dos CSC pelos governos e a evolução dos modelos de administração pública. A Nova Gestão Pública (NGP) favoreceu a adoção das práticas de serviços compartilhados no setor público ao preconizar a incorporação dos avanços da administração de empresas do setor privado.

$\mathrm{Na}$ gestão pública, os CSC permitem que os governos concentrem seus esforços em atividades de alto impacto para a sua missão, e não em funções administrativas rotineiras (Accenture, 2005a). Pesquisa realizada pela The Economist Intelligence Unit (2006), com 127 executivos do setor público envolvidos com CSC, revela que as principais motivações para a adoção do modelo são a redução de custos interdepartamentais, melhoria da satisfação dos cidadãos-clientes, implantação da agenda pró governo eletrônico e atendimento a outras exigências do governo (como o strategic sourcing).

Tomada a decisão pela implantação do CSC, os governos normalmente optam por quatro modelos (Tomkinson, 2007): intrasserviço, serviço, corporativo e supracorporativo.

O modelo intrasserviço - colaboração em um serviço específico ou especializado possibilita que um órgão ou vários órgãos do governo compartilhem uma parte de um serviço, formal ou informalmente. Não há transferência de risco e esse modelo é útil para gerar economia de escala, a exemplo da organização de compras.

No modelo serviço, geralmente, um órgão permite que outro preste um serviço de forma completa em seu nome, transferindo o controle e a responsabilidade. 
Essa transferência ocorre por meio de formalização adequada do relacionamento, mas o órgão tomador do serviço continua com o controle do orçamento.

No corporativo, dois ou mais órgãos se unem para compartilhar um serviço. Os parceiros formam um arranjo para prestação de serviços, com a devida formalização. Não apenas os benefícios são compartilhados, mas também os custos e a governança do CSC, de modo a assegurar o nível de serviço estabelecido.

No modelo supracorporativo, ocorre o compartilhamento com base na criação de um veículo de propósito específico para prestar os serviços. Os parceiros se unem e formam um arranjo para a prestação dos serviços. É criado um CSC (na qualidade de veículo de propósito específico), que agirá em nome dos parceiros. Os riscos são totalmente transferidos para o CSC, que fica responsável por todos os recursos envolvidos na prestação dos serviços.

A escolha de um desses modelos dependerá do tipo de necessidade, dos riscos envolvidos e da abrangência dos serviços a serem prestados. Também a forma de parceria dependerá do grau de complexidade e da estratégia de fornecimento de serviços escolhida (IPF, 2006).

Tomkinson (2007), discutindo os serviços prestados pelos CSC na administração pública na Inglaterra, enumera dez categorias relevantes: educação, transportes, receita e benefícios, lazer e bibliotecas, meio ambiente e proteção ao consumidor, rodovias, serviço social, serviços agrícolas, habitação e interdepartamentais. $\mathrm{O}$ autor menciona cinco serviços como sendo os mais frequentemente encontrados: rodovias, suprimentos, coleta de lixo, governo eletrônico e apoio a pessoas.

Quanto à esfera de governo onde se dá a utilização dos CSC, com base na experiência de países como Canadá,
Estados Unidos, Irlanda, Austrália, Inglaterra, Holanda, Alemanha, França, Itália, Espanha, África do Sul e Singapura, a literatura indica a existência dos CSC tanto na esfera federal quanto na estadual e municipal (Tomkinson, 2007; ACCenture, 2006).

Parece ser ainda incipiente o uso dos CSC no setor público brasileiro. As referências bibliográficas analisadas a partir de pesquisas nas bases de conhecimento científico revelaram a inexistência de relatos

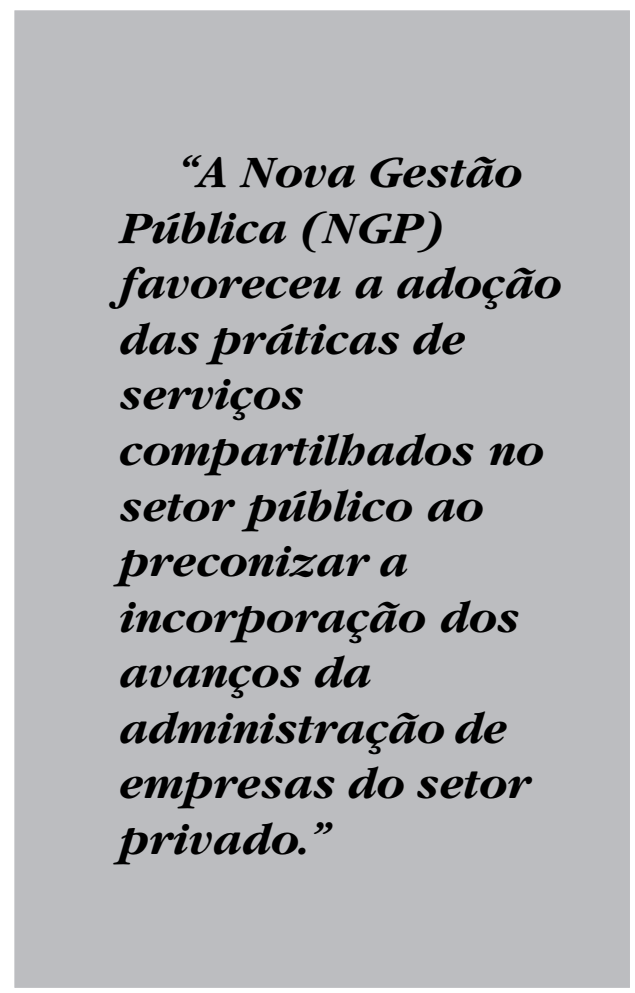

sobre a aplicação de centros de serviços compartilhados no setor público. Pesquisas complementares em fontes não acadêmicas resultaram na identificação de uma experiência denominada Unidade de Serviços Compartilhados (USC), no governo do Estado de São Paulo.

O Estado de São Paulo está trabalhando para instituir o Programa Integra São Paulo, que pretende reunir, em um 
único local, órgãos da administração direta e indireta, objetivando facilitar o atendimento aos municípios, órgãos públicos e entidades civis. Desse programa faz parte a USC (Unidade de Serviços Compartilhados), que deverá ser responsável pela gestão e execução de serviços relacionados a condomínio, segurança, portaria, manutenção predial e telefonia, para todas as secretarias (PGESP, 2009).

Em outra iniciativa afim, a Agência de Desenvolvimento Econômico do Grande $\mathrm{ABC}$, formada pelas sete prefeituras da região e outros atores sociais, está implantando centro de serviços de informação tecnológica, disponível para empresas da indústria do plástico (CIAP) e do complexo metal-mecânico (Cestec). Trata-se da tentativa de replicar a experiência italiana da região de Marche. (AgÊNCIA, 2009).

A implantação de um CSC no setor público é mais complexa do que no setor privado, pois, como lembram Janssen e Joha (2006), os motivos para implantação de um CSC na administração pública envolvem quatro lentes conceituais: estratégica/organizacional, política, técnica e econômica.

Pesquisa da IBM (2008b) destaca três principais dificuldades encontradas na implantação dos CSC na administração pública:

a) investimento inicial insuficiente, impedindo a continuidade do projeto e afetando significativamente o moral da equipe envolvida;

b) falta de compromisso com mudanças de longo prazo, devido aos ciclos eleitorais ou à transferência de agendas políticas; e

c) diferenças culturais ou de expectativas entre os "serviços sob demanda" (demand-driven), presentes no CSC e a filosofia de "serviço impulsionado pelo fornecimento" (supply-driven), usualmente presente na gestão pública.

A necessidade de se estabelecer uma nova cultura para a execução do modelo de serviços compartilhados é apontada como um dos temas críticos. Em particular, órgãos que utilizam os CSC são vistos como parceiros, porque a relação entre aqueles que executam uma tarefa e aqueles para quem a tarefa é realizada é vital para a consecução das metas da organização (Schulman et al, 1999).

Nessa direção, a referida pesquisa da IBM aponta cinco fatores críticos de sucesso para a implantação de um CSC na gestão pública:

a) forte competência em gerenciamento de projetos;

b) apoio da alta direção;

c) comunicação efetiva em todos os níveis;

d) abordagem em fases gradativas para a implantação; e

e) forte gestão da mudança para tratar as resistências e ajudar as pessoas a atravessarem o ciclo da transformação.

No setor público, a possibilidade de redução da força de trabalho é percebida como o obstáculo primordial por aqueles que estão considerando a adoção dos serviços compartilhados. No âmbito de uma iniciativa de serviços compartilhados, a estratégia de transição da força de trabalho é um meio e não um fim. Funciona melhor quando integrada com os elementos do plano de implantação dos serviços compartilhados, que normalmente inclui o detalhamento de descrições de novos cargos, novas competências exigidas, novos processos de negócio e especificações de novas tecnologias. Quatro medidas relativas à força de trabalho são apontadas como eventualmente necessárias: 
treinamento, realocação, aposentadoria e demissão (ACCENTURe, 2005b).

\section{A experiência britânica com centros de serviços compartilhados no serviço público}

O governo britânico estabeleceu a seguinte visão em seu programa de transformação administrativa:

Até 2016 a maioria dos elementos transacionais de Serviços Corporativos no setor público será entregue através de organizações profissionais de serviços compartilhados. Algumas destas organizações permanecerão no setor público, mas muitas serão terceirizadas (Essu, 2007).

A rigor, desde 1970 existe legislação que permite aos governos locais prover bens e serviços para outros governos locais, visando principalmente os benefícios do ganho de escala derivado das compras conjuntas. Outros atos legislativos vieram para aprimorar as práticas de trabalho colaborativo, como o Local Government Act 1972 and delegation; Local Government Act 2000 section 2 (wellbeing) and section 19; Local Government Act 2003 and trading \& charging; Local Authorities (Goods and Services) Act 1970 e EU procurement legislation (DCLG, 2006).

Entretanto, os primeiros CSC no serviço público surgiram efetivamente no final da década de 1990. A agenda para a eficiência estabelecida pelo governo britânico nos últimos 12 anos colocou os centros de serviços compartilhados como destaque das políticas públicas. Além disso, as autoridades locais desempenharam papel de liderança, que tem favorecido a criação dos CSC, não apenas entre governos locais, mas também com outras organizações do serviço público, incluindo arranjos como "The Local
Government Association", "Local Service Partnerships" e "Local Public Service Boards". Com os governos locais recebendo $75 \%$ do seu orçamento por meio de transferências do governo central, o ônus para uma melhor utilização dos recursos foi firmemente colocado nos conselhos locais. (Tomkimson, 2007; DCLG, 2006).

Os principais serviços prestados pelos CSC no serviço público britânico são:

a) serviços de back-office como finanças, tecnologia da informação, recursos humanos, folha de pagamento e outros serviços transacionais;

b) serviços sub-regionais como recolhimento e tratamento do lixo, que requer investimentos em larga escala, em nível regional ou sub-regional; e

c) serviços que podem ser combinados em bases geográficas para atingir economias de escala e cujo benefício advém da redução de despesas com viagens, por exemplo. (Tomkimson, 2007; NLGN, 2006).

O Shared Services Forum afirma que o governo inglês poderá economizar 40 bilhões de libras durante 10 anos pela concretização dos ganhos com serviços locais compartilhados de back-office. Para se ter uma ideia, existem 388 local councils na Inglaterra, com estruturas, status legal e portifólio de serviços muito parecidos.

O documento "Transformational Local Government", publicado em março de 2006 pelo governo britânico, instituiu ações que levaram os governos locais a incorporar as áreas de tecnologia da informação e comunicação no modelo CSC. Ademais, recomendou explicitamente a adoção dos CSC como 'ferramenta' para a eficiência. Vale destacar a consideração de que os benefícios financeiros da adoção dos CSC no setor público britânico serão obtidos em prazo maior do que no setor 
privado, devido, quase sempre, à impossibilidade de demissões imediatas para redução da força de trabalho, como possível decorrência do compartilhamento de recursos (TOMKIMSON, 2007).

Outros benefícios não monetários também são relatados, como:

a) aprendizado de melhores práticas pelos órgãos públicos participantes;

b) compartilhamento de investimentos, a exemplo de sistemas, que de outra forma seriam inacessíveis para alguns órgãos; e

c) obtenção de economias de escala e eficiências que reduzem os custos dos serviços (redução de locais, sistemas, equipamentos), possibilitando o redirecionamento das economias para o custeio de outros serviços públicos essenciais (ESSU, 2007).

De modo geral os CSC britânicos são constituídos com base em quatro princípios: 1) escopo e qualidade do serviço; 2) responsabilização democrática, governança e participação; 3) processos de serviços compartilhados e força de trabalho; e 4) investimentos públicos.

Uma tipologia com seis diferentes tipos de CSC foi definida para o modelo britânico: colaboração e compartilhamento de procedimentos, consolidação corporativa, liderança representativa, serviços cogerenciados, parceria estratégica e outsourcing ou offshoring. A tipologia é proposta com base no tipo de relacionamento entre as organizações do setor público (ESSU, 2007).

A colaboração e o compartilhamento de procedimentos são largamente difundidos entre governos locais. Por exemplo, uma pesquisa sobre a atual colaboração e compartilhamento de serviços na região de Yorkshire and The Humber identificou 157 iniciativas entre 22 autarquias locais (TOMKIMSON, 2007). Estão incluídos o trabalho conjunto em serviços para a infância, acordos recíprocos, procedimentos conjuntos, compartilhamento de melhores práticas, consórcio para a compra de livros e materiais audiovisuais, entre outros. A colaboração envolve, frequentemente, várias autoridades locais e outros órgãos públicos trabalhando juntos.

$\mathrm{Na}$ consolidação corporativa, uma organização, tal como um departamento do governo central, centraliza a função financeira, a tecnologia da informação e (ou) os recursos humanos em um ou mais centros de serviços, no âmbito regional ou nacional.

$\mathrm{Na}$ liderança representativa, uma autoridade é constituída em nome de um grupo de autoridades (por exemplo, fundos de pensão e tratamento de resíduos). Essa abordagem é geralmente baseada na prestação de serviços no próprio órgão (não terceirizada), embora no caso dos fundos de pensão também se inclua a terceirização da gestão de carteiras para instituições financeiras.

Os serviços cogerenciados envolvem um grupo de autoridades ou organismos públicos que estabelecem um projeto de serviços cogerenciados. Eles podem usar a mesma infraestrutura/ software e padrões comuns, continuando a prestar os serviços por si mesmos no curto prazo, em âmbito sub-regional ou regional.

$\mathrm{Na}$ parceria estratégica com o setor privado, diversos centros de serviços compartilhados regionais são conduzidos por provedores de serviços privados, como os conselhos de Somerset e Taunton Deane e a Polícia de Avon \& Somerset. Essas experiências são semelhantes às dos CSC do setor privado, que operam no Leste Europeu e em outras regiões.

Finalmente, na outsourcing ou offshoring, serviços são transferidos para uma empresa privada, visando a prestação contínua a um órgão público local, ou podem ser parcial ou totalmente transferidos para empresa privada fora da Grã-Bretanha, em localidades como Europa Oriental ou Ásia. 
A ESSU (2007) destaca barreiras para a implantação adequada de centros de serviços compartilhados na Grã-Bretanha, tais como: espaço político do governo local ou restrições relativas às fronteiras entre governos; compatibilidade de tecnologia e sistemas; empregabilidade vis a vis o conceito de democracia industrial; falta de evidências quantitativas dos custos e benefícios; requisitos de responsabilidade e transparência; estruturas organizacionais e cultura; financiamento multiórgãos públicos; impostos para organismos públicos não departamentais; regras para quantidade de empregados (em departamentos do governo central); regulamentação de suprimentos da União Europeia e impactos sobre o nível de emprego.

Outros aspectos críticos para a implantação dos CSC foram: a) a concentração de serviços corporativos e transacionais que, muitas vezes, leva a uma subavaliação da colaboração existente; b) o foco em atingir redução de custos, mas com fraca base de dados para comprovar os custos originais e os benefícios efetivamente atingidos; c) a ausência de preocupação com o impacto da estratégia de compartilhamento de serviços na economia regional e no nível de emprego; e (d) a abordagem inadequada sobre a ameaça de transferência de postos de trabalho para o exterior (Tomkimson, 2007; ESSU, 2007).

Do lado das práticas bem-sucedidas, destaca-se a criação de centros de excelência para centros de serviços compartilhados, reunindo especialistas, bem como colocados à disposição dos governos interessados, em todos os níveis, metodologias, casos práticos, técnicas, padrões, sugestões e um ambiente web para a colaboração em foros e grupos de estudo sobre o tema. Também são desenvolvidos seminários para a troca de experiências, comunicação e acompanhamento das principais iniciativas. Para exemplificar cabe mencionar o PSIF
- Public Service Improvement Framework - e os portais do NAO - National Audit Office - e do Cabinet Office Shared Services Team. Esse conjunto de recursos constituise em redutor da curva de aprendizagem e de custos para um órgão que deseje iniciarse no mundo dos CSC, ou mesmo aprimorar suas técnicas e atuação.

Considerações finais

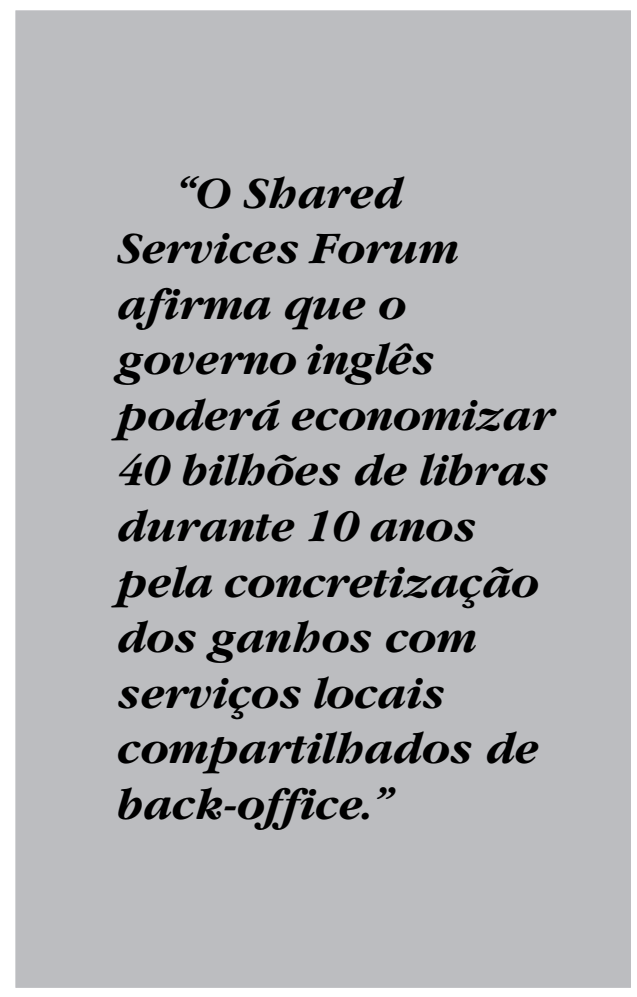

A pesquisa mostrou que as principais determinantes para o surgimento dos CSC na gestão pública residem nos âmbitos estratégico/organizacional, político, técnico e econômico. A análise da experiência britânica deixou evidente que, embora os CSC tragam contribuições para a melhoria da qualidade e para a redução de custo no serviço público, existem dificuldades importantes atreladas à integração das agendas 
políticas dos participantes, que podem impactar a velocidade de implantação e obtenção dos benefícios.

É elevado o grau de complexidade na implantação de um centro de serviço compartilhado no setor público, destacandose os seguintes problemas:

a) a padronização de políticas interdepartamentais;

b) a dificuldade de concretizar ganho de escala no curto-prazo, pois parte considerável desse é decorrente de redução de empregados, que no setor público contam com estabilidade de emprego; e

c) a dificuldade de comprovar os benefícios alcançados devido à inexistência de informações acuradas sobre os custos e volumes atuais.

Embora os CSC estejam presentes há pouco tempo no serviço público, já demonstram seu poder transformador na reestruturação dos governos para atender às necessidades do funcionalismo, dos cidadãos e das empresas, seja em serviços internos ou para atendimento à comunidade. A qualidade do gasto público estará cada vez mais na pauta do serviço público nos próximos anos. Também deve elevarse a expectativa em torno da qualidade do serviço, de sua efetividade e da transparência do poder público.

O compartilhamento de serviços é uma decisão estratégica que tem impacto a longo prazo. É esperado que o compartilhamento de serviços seja menos focado em questões tecnológicas e cada vez mais em questões organizacionais e de governança, cruzando, portanto, fronteiras organizacionais e jurisdicionais.

No caso brasileiro verifica-se que o potencial de benefícios pode ser expressivo. Tomando-se como base, por exemplo, o governo federal, pode-se ter uma ideia da magnitude dos benefícios potenciais ao analisar-se a folha de pagamento do funciona- lismo, que atinge cerca de $\mathrm{R} \$ 155$ bilhões por ano. Caso a solução CSC traga 10\% de redução de custos sobre essa base, poderiam ser convertidos cerca de $\mathrm{R} \$ 15$ bilhões anuais com despesas de custeio em investimentos.

O Brasil está caminhando rumo às melhores práticas de serviço público e, à medida que avança na direção de modelos organizacionais tecnicamente mais complexos e gerencialmente mais qualificados (Denhardt; Denhardt, 2007), mais demandará soluções como as oferecidas pelos CSC. Por outro lado, iniciativas como o governo eletrônico, crescentes no país, naturalmente clamam por uma revisão dos processos e da forma de organização dos serviços públicos, levando à discussão de soluções do tipo CSC. Os CSC também podem ser utilizados como instrumento para a melhoria da qualidade dos serviços (por exemplo, coleta e tratamento de lixo) e compartilhamento de investimentos entre municípios de uma determinada região. Com o advento da lei dos consórcios públicos, deve haver um estímulo crescente ao surgimento de CSC nas diversas esferas de governo, num primeiro momento intraesfera, passando posteriormente a experiências e iniciativas inter-esferas.

Vale destacar que o Decreto 6.932/ 2009 , visando a simplificação do atendimento prestado ao cidadão, estabelece como diretrizes:

a) o compartilhamento de informações e a atuação integrada e sistêmica entre os órgãos e entidades do Poder Executivo Federal; na expedição de atestados, certidões e documentos comprobatórios de regularidade; e

b) a articulação com estados, Distrito Federal, municípios e outros poderes para a integração, racionalização.

Ademais, o referido decreto torna obrigatória a publicação das "cartas de serviços ao cidadão" para organizações do 
Executivo Federal que atendem ao público, com o objetivo de informar o cidadão dos serviços prestados pelo órgão, das formas de acesso a esses serviços e dos respectivos compromissos e padrões de qualidade de atendimento ao público.

Finalmente, para contribuir com a visão de futuro dos CSC na gestão pública, cinco tendências apontadas por Janssen e Joha, Tomkinson e pelo ESSU são destacadas:

1) Os serviços providos pelos CSC tenderão a ser mais efetivos graças ao acesso à expertise, melhores práticas e parcerias. $\mathrm{O}$ uso de centros compartilhados tem sido inicialmente limitado aos serviços com padronização simples. No futuro, o âmbito de aplicação deve ser ampliado e órgãos públicos poderão compartilhar processos completos de back-office. Mesmo aparentemente diferentes serviços podem ser compartilhados, como finanças, contabilidade, compras e recursos humanos. Além disso, a identificação de necessidades ocorrerá de forma explícita e latente, de modo que os serviços atendam de fato à expectativa dos clientes.

2) Os processos de negócios na iniciativa privada passam por uma nova revolução com a utilização das técnicas, ferramentas e melhores práticas de BPM (Business Process Management). Essa tendência deverá se refletir no serviço público, que poderá beneficiar-se da gestão efetiva de processos, com consequente aumento de qualidade, redução de riscos e aderências às regras (compliance).

3) Tanto mais maduro um CSC, mais automatizado ele estará, podendo oferecer um novo patamar de serviços, onde clientes, funcionários e fornecedores podem se autoatender mediante as tecnologias que aproximam o governo e a sociedade. Tecnologias como BPMS (Business Process Management Suite), ERP (Enterprise Resource Planning), web 2.0, social networking e governo eletrônico criarão ambientes favoráveis à colaboração e à inovação.

4) Os profissionais do serviço público terão cada vez mais acesso a técnicas, experiências e ferramentas utilizadas em CSC e esse compartilhamento de conhecimento deverá implicar a evolução do perfil desses profissionais. Isso deverá refletir-se na melhoria dos serviços prestados.

5. Os novos modelos de governança deverão adotar a postura de convidar o 'cliente' para participar efetivamente da gestão e aprimoramento dos CSC. Também os modelos de governança tenderão a assegurar que os ganhos de eficiência sejam de fato compartilhados pelos participantes e a transparência obtida por meio dos SLA (Service Level Agreements) e relatórios de desempenho/resultados publicados regularmente via internet.

Certamente a próxima década trará relevantes inovações no campo da gestão pública, com um espaço potencialmente importante para os serviços compartilhados. Concluímos destacando duas oportunidades que se abrem para futuras pesquisas. Em primeiro lugar, a investigação do relacionamento entre os stakeholders e os mecanismos de governança dos CSC na gestão pública. Em segundo lugar, a utilização dos consórcios públicos como vetores de CSC no caso brasileiro.

(Artigo recebido em janeiro de 2010. Versão final em dezembro de 2010). 


\section{Referências bibliográficas}

Accenture. Driving High Performance in Government. New York: Accenture, 2005a. . Rites of Passage: How to Launch a Successful Shared Services Program in the Public Sector. New York: Accenture, 2005b.

. Implementing Shared Services in the Public Sector: The Pillars of Success. New York: Accenture, 2006.

Agência de Desenvolvimento Econômico do Grande Abc. Centro de Serviços em Tecnologia e Inovação do Grande $A B C$. Disponível em: <http://www.agenciagabc.com.br/ noticias.asp?id=1436\&rel=1436\&classificacao=2>. Acesso em: 28 jun. 2009.

BAIN \& Company. Centros de serviços compartilhados: uma solução definitiva para os processos administrativos? São Paulo: Bain \& Company, 2004.

Bergeron, B. Essentials of Shared Services. New Jersey: John Wiley \& Sons, 2003.

Bywater Consulting. Realizing the potential of shared services. Stamford: Bywater, 2001.

Department for Communities and Local Government. Structures for Collaboration and Shared Services. London: DCLG, 2006.

Deloitte. Centros de serviços compartilhados: tendências em um modelo de gestão cada vez mais comum nas organizações. São Paulo: Deloitte, 2007.

Denhardt, Janet V.; Denhardt, Robert B. The New Public Service: Expanded Edition. New York: M. E. Sharpe, 2007.

Economist Intelligence Unit, The. Evaluating Public Sector Shared Services. London: The Economist, 2006.

Essu. European Services Strategy Unit. Shared Services in Britain. London: Essu, 2007.

Ibm Global Business Service. The Global CFO Study 2008. New York: IBM, 2008a. . Success Factors for Implementing Shared Services in Government. Washington, D.C.: IBM, 2008b.

Institute Of Public Finance and Accountancy. Shared Services: The Opportunities and Issues for Public Sector Organisation. London: IPF, 2006.

Janssen, M.; Joha, A. Motives for Establishing Shared Service Centers in Public Administrations. International Journal of Information Management, v. 26, n. 2, p.102-116, 2006.

Decisions and design choices for the development of shared services arrangements and its relationships. In: ANNUAL ISOne WORLD CONFERENCE, 6, 2007, Las Vegas. Proceedings... Las Vegas (Nevada), 2007. p. 1-16.

. The Strategic Determinants of Shared Services. In: Garson, G. D.;

Khosrow-Pour. Handbook of Research on Public Information Technology. New York: Information Science Reference, 2008.

New Local Government Network. The Politics of Shared Services: What are the underlying barriers to a more successful shared services agenda? London: NLGN, 2006.

Portal do Governo do Estado de São Paulo. Estado de SP institui centros regionais de governo. Disponível em: <http://www.saopaulo.sp.gov.br/spnoticias/lenoticia.php?id= 101295\&c=6>. Acesso em: 21 jun. 2009. 
Quinn, B.; CoOKE, R.; KRIS, A. Shared Services: mining for corporate gold. Harlow, Essex: Prentice Hall, 2000.

Selltiz, C. et al. Métodos de Pesquisa nas Relações Sociais. Tradução de Dante Moreira Leite. 3 ed. São Paulo: Editora da Universidade de São Paulo, 1974.

Schulman, D. S. et al. Shared Services. Adding Value to the Business Units. New York: John Wiley \& Sons, 1999.

TomkInson, Ray. Shared Services in Local Government: improving service delivery. Hampshire: Gower Publishing, 2007. 


\section{Resumo-Resumen-Abstract}

Centros de Serviços Compartilhados: da experiência britânica às perspectivas de inovação na Gestão Pública Brasileira

Cicero Ferreira, Luiz Paulo Bresciani e Leonel Mazzali

O presente artigo toma como ponto de partida a revisão do estado da arte sobre os centros de serviços compartilhados (CSC). Arranjos de serviços compartilhados estão ganhando importância na gestão pública como meio para reduzir despesas e elevar a qualidade dos serviços. Os objetivos da pesquisa foram investigar as determinantes do surgimento dos CSC na gestão pública, os principais problemas em sua implantação e as tendências futuras dos CSC. Além da publicação científica e técnica sobre o tema, a metodologia se assenta no estudo da experiência britânica de compartilhamento de serviços entre diferentes esferas de governo. Uma das conclusões relevantes da pesquisa é que o Brasil, embora tenha poucas experiências de serviços compartilhados na administração pública, poderá obter significativos benefícios financeiros e na qualidade dos serviços públicos.

Palavras-chave: Centros de serviços compartilhados; operações de serviços; consórcios públicos.

Centros de Servicios Compartidos: de la experiencia británica a las perspectivas de innovación em La Gestión Pública Brasileña

Cicero Ferreira, Luiz Paulo Bresciani e Leonel Mazzali

Este artículo toma como punto de partida la revisión del estado del arte acerca de los centros de servicios compartidos (CSC). Los servicios compartidos están ganando importancia en la administración pública como un medio para reducir costes y elevar el nivel de servicio. Los objetivos de la investigación fueron de investigar los factores determinantes de la aparición de CSC en la administración pública, los principales problemas en su aplicación, y las tendencias futuras de los CSC. Además de las publicaciones científicas y técnicas sobre el tema, la metodologia examina en profundidad el caso británico de servicios compartidos entre los diferentes niveles de gobierno. Una de las conclusiones de la investigación es que CSC puede aportar importantes beneficios cualitativos y cuantitativos para el servicio público de Brasil.

Palabras clave: Centros de servicios compartidos; nuevo servicio público; consorcios públicos.

\section{Shared Service Centers: from British experience until the prospects for innovation in Brazilian Public Administration \\ Cicero Ferreira, Luiz Paulo Bresciani e Leonel Mazzali}

This article takes as its starting point the shared services centers (SSC) state of the art review. Shared services centers are gaining importance in public administration in order to reduce costs and to raise the services quality. The research objectives were investigate the determinants of occurrence of SSC in public administration, the main problems in their implementation and the future trends for SSC. Besides the scientific and technical publication on the subject, the methodology examines the British case of services sharing among different spheres of public administration. It is concluded that Brazil, although has few shared services experiences in the government sector, can get significant financial benefits and increasing services quality with the use of SSC in the public sector.

Keywords: Shared service centers; service operations; new public service. 


\section{Cícero Ferreira}

Doutorando em Administração de Empresas pela University of Liverpool e mestre em Administração pela Universidade Municipal de São Caetano do Sul (USCS). Consultor em gestão empresarial especializado em operações de serviço. Contato: cicferreira@uol.com.br

Luís Paulo Bresciani

Doutor em Política Científica e Tecnológica pela Universidade Estadual de Campinas (Unicamp). Professor doutor do programa de pós-graduação em Administração da USCS e Secretário de Desenvolvimento Econômico e Trabalho de Diadema. contato: lpbresciani@uscs.edu.br

Leonel Mazzali

Doutor em Economia de Empresas pela Escola de Administração de Empresas de São Paulo, da Fundação Getúlio Vargas (EAESP-FGV). Professor doutor do programa de pós-graduação em Administração da USCS. Contato: leonel_mazzali@uol.com.br 


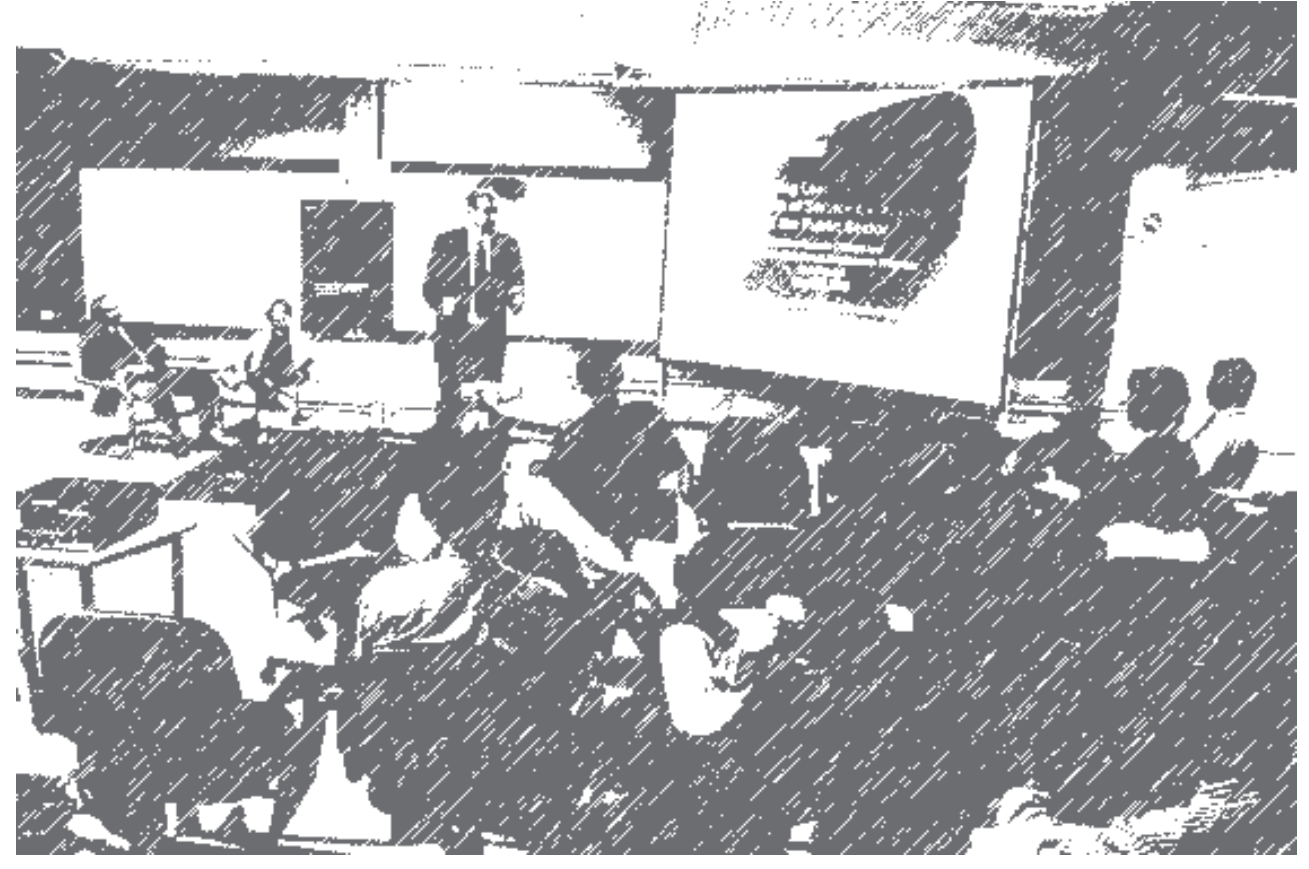

